\title{
Veterinarians between the Frontlines?! The Concept of One Health and Three Frames of Health in Veterinary Medicine
}

\author{
Martin Huth $^{1}$ (D) Kerstin Weich ${ }^{1} \cdot$ Herwig Grimm ${ }^{1}$
}

Accepted: 2 May 2019 / Published online: 24 May 2019

(C) The Author(s) 2019

\begin{abstract}
The "One Health" initiative promises to combine different health-related issues concerning humans and animals in an overarching concept and in related practices to the benefit of both humans and animals. Far from dismissing One Health, this paper nevertheless argues that different veterinary interventions are determined by social practices and connected expectations and are, thus, hardly compliant with only one single conceptualization of health, as the One Health concept suggests. One Health relies on a naturalistic understanding of health focusing on similar bodies that show a similar etiology. However, logics, normativity, and practices exhibit differences when it comes to combatting infectious diseases, maintaining productivity of livestock animals or preventing companion animals from suffering. Therefore, drawing from Charles Rosenberg's groundbreaking texts on framing disease, we suggest to conceive of health as dispersed in different frames. Thus, this paper proposes to interpret health as complex and multi-layered concept. We distinguish and introduce an objectivist, a functional, and a sentientistic frame of health. Instead of reducing the differential veterinary practices to one paradigmatic understanding, health is seen as a model case of Wittgenstein's concept of family resemblance. Different and distinct perspectives on veterinary medicine show sufficient overlapping that allows for a common conceptualization, but there is not one single underlying logic suitable to understand and ethically reflect all veterinary interventions. This differentiability promises to reduce moral stress in veterinary professionals since it allows the interpretation of various, seemingly contradicting practices as dependent on multi-layered and socially determined scopes of responsibility.
\end{abstract}

Keywords One health · Disease $\cdot$ Illness $\cdot$ Family resemblance $\cdot$ Justification of treatments

Martin Huth

martin.huth@vetmeduni.ac.at 


\section{Introduction: Beyond the Scope of One Health}

In practice, there is more than one world, and likewise more than one health. (Hinchliffe 2016: 31)

Veterinarians as professionals in food chains are first and foremost responsible for health, and preventing and treating disease. This responsibility comprises the health of animals used in food production (individuals or herds and flocks), but also the animal owners' and public health (by combatting zoonotic diseases in animals), the health of consumers (by combatting food-borne diseases), and environmental health (by combatting epizootics and pollution). In turn, we can conceive of health as the basis for the justification of veterinary treatments. Basically, veterinary treatments are often interventions in the body of a living being; sometimes harmless (like administrating drugs or stitching up a wound), but potentially severe, lifethreatening (major surgeries) or even terminating life (euthanasia; humane endpoints in animal experiments; stamping-out in the case of epidemics). Interventions are supposed to be permitted only if health is aimed for or if allegedly superior goals are deemed to outweigh animal health, e.g. economic concerns or the health of humans overriding animal health (Huth 2016). Hence, one can state that the concept of health presents a powerful teleological figure ${ }^{1}$ that builds the moral legitimization for veterinary practices (Nordenfelt 2006: 5; Schramme 2017: 121).

However, depending on the various contexts of veterinary treatment, health is obviously dispersed in the dimensions of the individual animal, herds and flocks, animal owners, consumers, the public sphere, and the environment. Thus, there is not only one perspective from which health is aimed for in veterinary medicine. Social expectations towards veterinarians (as well as legal frameworks) differ significantly when considering various practices. Here are three telling examples: Firstly, combatting zoonotic diseases as a threat for public health or epizootics as a threat for profitability of a broader agricultural community can shift the perspective of veterinary practice from the individual animal to populations and broader economic structures (Buller 2017: 433). In infectious diseases, protecting human or nonhuman populations seems to be the primal expectation towards veterinarians and the main justification for interventions. This can happen at the expense of individual health or even life. Therefore, even prophylactic culling is a frequent measure to eradicate pathogens although this does not always go uncontested (Cohen and Stassen 2016). Secondly, treating fertility disorders in dairy cows is but one example of a practice that roots in the expectation to primarily regain productivity against the backdrop of economic pressure due to tight margins (Hinchliffe et al. 2017). If bodily malfunctions of dairy cows impair productivity, the emphasis is put on regaining or maintaining cost efficiency while potentially neglecting the animal's experience of illness or wellbeing. Thirdly, preventing companion animals from suffering and aiming for their good quality of life is deemed the primary veterinary obligation in small animal practice. There is a number of interventions in pets that are actually the outcome of human aesthetic preferences. Moreover, we face the problem of convenience euthanasia (Rollin

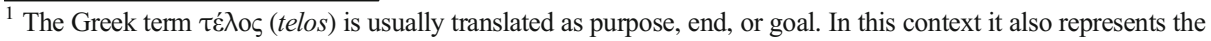
basis of justification of veterinary intervention. Although one has to acknowledge that not all medical treatments are pursuing health goals (e.g. in cosmetic surgeries or artificial insemination), most of the interventions in bodies are legitimized by their orientation towards recovery from a disease.
} 
2006). However, achieving companion animals' wellbeing seems to form the main expectation and justification of treatment, potentially even overriding the aim to avoid an "untimely death" when it comes to euthanasia understood as mercy killing (Grimm and Huth 2016). Consequently, we proceed from the assumption that there is not one unequivocal orienting goal of veterinary medicine and that health is framed by different social practices with different normative implications.

However, particularly in the last decade, ${ }^{2}$ different health-related concerns have been increasingly dealt with under the aegis of One Health $(\mathrm{OH})$. The basic idea is to develop an overarching concept of health that is deemed to root in the shared etiology and a possibly equal medical treatment of humans and animals. Therefore, Zinsstag et al. describe $\mathrm{OH}$ as follows: "The convergence of interests in human and animal health, based on careful observation and scientific study, has been recognized and promoted by luminaries in the field of health sciences" (2015: 16). In addition, OH presents a "new professional imperative" (AVMA 2008: 3) for veterinarians that should be regarded as the ethical benchmark for their professional practice. The basic assumptions behind this imperative are that (a) humans and animals are equal or at least similar with regard to the etiology of disease and their health related needs; (b) these needs are interdependent and can coexist without friction in practice; (c) the treatment of humans and animals can follow the same logic and procedures in different contexts like combatting infectious diseases, maintaining productivity of livestock animals or maintaining wellbeing of companion animals. These assumptions entail a number of promises that are, among others, (a) to decrease or even solve antagonisms between humans and animals with regard to health; (b) to reduce the veterinarians' moral distress of balancing between different, allegedly mutually exclusive needs; (c) to support veterinary practice by transferring knowledge from human to veterinary medicine (Whittaker 2015). The major aim of the development of $\mathrm{OH}$ is not only a more efficient sustenance of human health by acknowledging our dependency on animals and environment. Such a stance would interpret the value of animals as merely instrumental. By contrast, $\mathrm{OH}$ seeks to support the respect for animals recognizing them "as part of an overall effort to maintain sustain ecosystem integrity and, thus, comprehensive well-being” (Zinsstag et al. 2015: 20).

However, the main objective of this paper is to argue that $\mathrm{OH}$ cannot live up in all respects to the complexity of veterinary practice and the multidimensional nature of health. Arguably, $\mathrm{OH}$ runs the risk to conceal or even to reinforce moral difficulties since it represents a naturalistic and monistic idea of health. This naturalism tends to neglect the differences between social practices and their moral implications with respect to different animals. Our most basic assumption is that the triad of animal - owner - veterinarian is inevitably embedded in social practices. Therefore, clinical encounters cannot be understood independently of social practices and expectations that predetermine the scope of decision-making and treatment. But if we conceive of health and veterinary responsibility in a monistic way (as in $\mathrm{OH}$ ), then the professional life of veterinarians appears to be full of insurmountable moral inconsistencies between livestock animals and companion animals. Finding oneself in this alleged ethical trap might entail pernicious moral distress (Verweij and Meijboom 2015; Fawcett and Mullan 2018).

\footnotetext{
${ }^{2}$ Actually, the idea of $\mathrm{OH}$ traces back to much earlier sources. Initial attempts to promote the convergence of health between the species had been visible already in the ancient world and then reoccurred by the dawning of modern times (Bresalier et al. 2015: 2).
} 
In what follows, we will introduce three structural models of health that tacitly organize veterinary practice and its various aims: the objectivist, the functionalist, and the sentientistic frame of health. ${ }^{3}$ These differential conceptualizations constitute different scopes and different patterns of justification of veterinary interventions.

The investigation will be pursued in three steps. First, the concept of health will be analyzed with regard to its justificatory power and as a teleological figure. Therefore, the most influential traditional definitions of health will provide the point of departure. Second, the three models of health will be put forward. Third, proceeding from the differential frames of health developed in the second step, the concept of health in veterinary medicine will be reconsidered against the backdrop of Wittgenstein's concept of family resemblance. This also forms a prerequisite for a reconsideration of the concept of $\mathrm{OH}$.

\section{The Concept of Health and its Different Definitions}

"Health" presents an "elusive concept" (Forrest 2014: 209) since it has been conceived of in quite different ways. In the following, three influential definitions of health will be introduced and serve as stepping stones for the upcoming considerations:

(i) Christopher Boorse famously develops the naturalistic concept of health. Health presents a merely descriptive, prima facie value-free concept (Boorse 1977: 547; 1997: 7-8; similarly Broom 2007 with respect to animals). Boorse sums up his account in four points: (a) Primarily, one has to refer to a reference class that is conceived as a natural class of organisms, representing an age group or a sex group of a certain species. (b) Starting point is the normality of physiological functions. This equals a statistically typical contribution to individual survival and reproduction. (c) Disease represents an impairment of a normal functional ability. (d) Health represents the absence of disease (cf. Boorse 1997: 7-8). Hence, health is a characteristic of a body that conforms to a particular "species design" (Nordenfelt 2006: 11). Any physiological function is either in line with the statistical normalcy or it is abnormal and, thus, pathological. Health and disease are conceived of as natural occurrences that are regarded as logically independent of ethical or social frameworks. ${ }^{4}$

Arguably, $\mathrm{OH}$ draws implicitly from such an idea of naturalizing health. Although health is, in contrast to Boorse's approach, conceived of as professional (ethical) imperative and thus not "value-free", it is apprehended as a biomedical fact. Proceeding from the assumption of a shared etiology in humans and animals, the focus is directed at shared physiological processes or common susceptibilities to pathogens. Even though we acknowledge the important critical

\footnotetext{
${ }^{3}$ The investigation draws from, but also modifies and refines Martin Huth's account of a multi-layered health concept (2016). Earlier, Bernard Rollin already introduced the famous distinction between the models of the veterinarian as mechanic and the veterinarian as pediatrician-like (2006: 27). The upcoming consideration will go one step further in showing that the complexity of veterinary practice exceeds the binary distinction of kinds of practices.

${ }^{4}$ Drawing from Canguilhem, we suspect that a normatively neutral, entirely descriptive conception of health simply does not exist. Canguilhem has famously indicated that the concept "normal" inevitably shimmers between statistical normalcy and a normative teleology that suggests what should be the case (Canguilhem 1989: 44).
} 
intention of $\mathrm{OH}$, we would like to point out that social expectations and their normative implications are not sufficiently covered by the debates on $\mathrm{OH}$. Particular, different relations between humans and animals are not taken into account. $\mathrm{OH}$ is the attempt to develop one generalizing concept to subsume different health-related matters under one category. However, this seems to lead to the claim that one etiology should entail one moral obligation. Yet exactly this, so our argument goes, can lead to the experience of a logically and ethically inconsistent practice with pernicious psychological implications. Veterinarians find themselves confronted with extremely different expectations. If a single professional imperative tells them to pursue equality in the treatment of animals without sufficient attention to different fields of practice, moral distress can be even increased.

(ii) Constructivism regards health (and disease) as a socially determined concept. Healthy or diseased are those bodies that are declared as healthy or diseased (Engelhardt 1975). In contrast to naturalism, in constructivism moral implications are part of the health concept itself. However, in this approach the body and its ailment seem to be concealed. Constructivism potentially leads to a social arbitrariness of justifications of (veterinary) medical practices. We can see that from a historical perspective in which homosexuality or drapetomania (slaves' drive to escape) have been conceived of as diseases. Likewise, if behavioral problems in livestock animals - due to density and deprivation of possibilities to exercise natural behaviors - were regarded as a "typical occurrence", there would be no justification to consider them as pathologies and, consequently, to take action in terms of cure or prophylaxis. Therefore, any attempt to implement $\mathrm{OH}$ as a professional imperative under the aegis of constructivism would be reliant on the hegemonic discourse on humans and animals and their health. The treatment of animals would then be strictly dependent on how they are conceived of in our society in a given situation.

(iii) Charles Rosenberg introduces the concept of frames in the debates about health (Rosenberg 1989, 1997). His account seems to present a middle position between naturalism and constructivism. "[D]isease is at once a biological event, a generationspecific repertoire of verbal constructs reflecting medicine's intellectual and institutional history, an occasion of and potential legitimation for public policy, an aspect of social role and individual - intrapsychic - identity, a sanction for cultural values, and a structuring element in doctor [or veterinarian, $\mathrm{MH} / \mathrm{KW} / \mathrm{HG}$ ] and patient interaction ${ }^{5}$ " (Rosenberg 1997: xiii). In the vein of Steve Hinchliffe et al., one can indicate that a frame is not a mere representation but a way of bringing health or a specific disease into being (2017: 27). Socio-cultural discourses, concepts, and practices impose mechanisms of foreclosure upon an otherwise opaque body (cf. Rosenberg 1997: xvii). To give an example, depressions in dogs are nowadays considered as pathology with clear signs (e.g. uncontrolled urinating, refusal to eat etc.). However, it is likely that some decades ago psychological problems in companion animals would not have been recognized. Moreover, depression is not a diagnosis that is regularly made in fattening pigs as the focus of veterinary treatment is differently and as mild behavioral problems might be regarded as normal under industrialized keeping conditions.

\footnotetext{
$\overline{5}$ This makes visible that the triad of animal - owner - veterinarian is embedded in a socio-cultural context.
} 
A frame constitutes disease as a disease; it is at the same time an epistemological function (what allows us to identify a phenomenon as a pathology) and a normative basis for treatments. It preserves "natural" and "social" elements as well as moral implications in the concept of health. Normative and descriptive dimensions are combined, within the concept of health bodily states are inextricably linked to social practices and moral significations: the latter frame the former.

For the upcoming considerations, Rosenberg's account will be significant as it allows us to conceive of health as differentially framed. We assume that there is not one frame but a variety of coexistent frames, partly overlapping, partly in tension (similarly, Hinchliffe et al. propose to understand the notion of disease as constituted through variegated "disease diagrams", 2017: 26). It becomes possible to understand health as a complex, multi-layered concept that operates as an umbrella term bearing diverse notions of health. This variation roots in the difference of (normatively imbued) roles of animals. Hence, the concept of frames becomes the point of departure for a relational theory of health. Health and disease are to be understood as embedded in social structures but also as "social actor[s], that is, a factor in a structured configuration of social interactions" (Rosenberg 1997: xx). While OH seems to presuppose health and disease as unequivocal and naturally given, we want to point out that differences occur within the concept of health itself. There are variegated aims and justifications of veterinary treatments within different fields of human-animal relations. Consequently, the triad of animal - owner - veterinarian is not a distinct given. It is reliant on and embedded in the relevant frame of health and its practical and ethical implications. This will be analyzed and exemplified in the upcoming section.

\section{Three Frames of Health in Veterinary Medicine ${ }^{6}$}

In what follows, three frames or models of health will be introduced as structural models. Similarly to Linda and Ezekiel Emanuel's four models of the relationship between physician and patient (1992), they are not intended to present exact descriptions. As structural models they are neither existent in pure form nor as entirely separated from each other. They serve as types to capture the differential normative infrastructure of veterinary medicine.

The models are developed by means of a narrative heuristics: Imagine three siblings, Olivia, Felicity, and Steven, in different relations to animals. Each of them is concerned about health. However, this concern is rooted in and determined by different perspectives and needs that entail different (practical and ethical) expectations towards veterinarians. It will become visible that health and likewise veterinary medicine are embedded in a "world made in various, sometimes overlapping, but rarely coherent, practices. That is, if we believe that things [e.g. health, M.H./K.W./H.G.] are made through their relations, or change as they relate to one another" (Hinchliffe 2016: 30). We will argue that each of these cases opens a particular perspective on health and disease and entails a specific set of moral expectations. Each of these perspectives and its normative implications presents a particular frame of health in veterinary medicine.

\footnotetext{
${ }^{6}$ The upcoming considerations are decisively modified reflections on the different conceptualization of health initially introduced by Martin Huth (2016).
} 
(i). Olivia is an official veterinarian who is currently concerned with an outbreak of foot-andmouth disease (FMD). She is in charge of decision-making concerning appropriate countermeasures against the backdrop of relevant legal regulations, public expectations, and customary practices. Moreover, she knows that she acts according to economic constraints of livestock farmers and on the basis of laws that protect economic ends and even prefer them to animal health.

(ii). Her sister Felicity is a dairy farmer. She is, from her point of view, economically dependent on the veterinarian's competence to maintain her cows' capacity to be productive. Diseases like mastitis or fertility disorders build a vital threat to her since her (and generally) calculations are tight. At the moment, she has to cope with a case of Bovine Ovarian Cyst that hinders one of her cows to become pregnant which would of course be indispensable for lactation.

(iii). Steven, their brother, is a trained philosopher who is animal-loving. He considers his pug a true family member. From his philosophical stance, he is convinced that his pet dog is a conscious being with interests and has an independent moral status. ${ }^{7} \mathrm{He}$ likewise expects the veterinarian he is consulting to acknowledge this moral status without compromises. Recently, it has turned out that his dog is overweight.

\section{(i). The Objectivist Conceptualization of Health: Health as Part of a Whole}

Basically, Olivia as an official veterinarian finds herself in the frontline of combatting epidemics and zoonoses. At first glance, the current outbreak of FMD might even appear as a benign case of decision-making with regard to combatting infectious diseases since it is conceived of as an epizootic, not as a zoonosis (human infections are rare and usually show a mild course). By contrast, take the examples of H5N1, a Highly Pathogenic Avian Influenza Virus (HPAI, building a possible threat for human populations; Degeling et al. 2016) or of Campylobacter infections (causing diarrhea after the consumption of poultry, hence, a food safety issue; Hinchliffe et al. 2017).

Pertinent expectations towards Olivia and her colleagues are visible in public debates as well as among experts in the field and comprise e.g. public health in general, food security, economic concerns, and animal welfare. To deal with these variegated expectations, it seems crucial to abstract from individuals' experiences and weigh different health-related matters. These matters are not recognized equally but differentially (Huth 2018). In case of the outbreak of a severe zoonotic disease, most people would consider it cynic to put the bird population before e.g. children (who are particularly susceptible to dangerous infections). Consequently, the management of zoonoses appears to be unambiguous concerning the decision-making in favor of humans. One tends then to tacitly reduce the animals to threatening zoonotic vectors, that is, objects caring pathogens that are to be eradicated (Haraway 2008). This reductionism mirrors a particular understanding health. From a naturalistic point of view one can proceed from the fact that there is a possible transmission of pathogens from animals to humans and vice versa. Similar bodies show a similar and interconnected etiology. Unsurprisingly, $\mathrm{OH}$ initially emerged within the field of combatting infectious diseases. In the wake of its

\footnotetext{
${ }^{7}$ It would be possible to elaborate on a particular ethical theory that would ground a moral status (be it a deontological position arguing towards animal rights or a utilitarian approach arguing towards the implementation in a weighing of interests). For the purpose of this paper it suffices to proceed from the assumption that Steven considers his pug to be a person whose existence and well-being entails far-reaching moral obligations on the part of humans.
} 
commitment to $\mathrm{OH}$, the AVMA exemplarily emphasizes the intertwining of humans and animals with regard to health: "[O]f the 1461 diseases now recognized in humans, approximately $60 \%$ are due to multi-host pathogens characterized by their movement across species lines. And over the last three decades, approximately $75 \%$ of new emerging human infectious diseases are defined as zoonotic. Our increasing interdependence with animals and their products may well be the single most critical risk factor to our health and well-being with regard to infectious diseases." (AVMA 2008: 3).

To put it pointedly, from this perspective, our relation to animals consists in a shared susceptibility to microbes and our spatial proximity to them. Therefore, Olivia can address the question what she ought to do as an official vet under the aegis of $\mathrm{OH}$. It is obvious that the AVMA refers in this case to an understanding of health and disease within the transmission paradigm (Hinchliffe et al. 2017). In a naturalistic air (similarly to Boorse's approach), disease traces back to a contamination of a previously unadulterated body with pathogens (Huth 2018). Neither the species nor the individual and particular manifestations of an infection make the difference. The pathological phenomenon as well as any kind of ailment is conceived of as secondary. Hence, subjective illness (the lived experience of being sick) is in tends to be concealed by disease (the "objective" existence of an aberration, in this case an adulteration). ${ }^{8}$ The body is reified as an object that should not be adulterated and disturbed by detrimental microbes. Olivia's pursued targets of interventions are bodies (objects) and microbes.

Consequently, countermeasures comprise locking out (by material barriers) or, in case of an outbreak, eradicating pathogens. This is possible by means of medical treatment; $\mathrm{OH}$ can serve as a valuable basis for this as it supports the development of drugs and other kinds of treatment of one disease by referring to different species (human and non-human) and transferring knowledge from one to the other.

One could argue that vaccination would be the most effective way to avoid the "pathogenicity" (Hinchliffe et al. 2017: xiv) of specific microbes. This can be regarded as part and parcel of the mentioned barriers to protect humans and animals from contagion. However, vaccination frequently turns out to be too complicated, too expensive or too insecure (Mepham 2016). Hence, the eradication of pathogens remains a crucial countermeasure in the face of infectious diseases. Notably, hosts are in such cases primarily conceived of as (mere) zoonotic vectors. By taking this stance, the subjectivity of the host becomes concealed, the animal becomes a mere object. Therefore, the eradication of pathogens can and does frequently entail the eradication of the actual host or even the possible host. Though there is frequent criticism of practices of (prophylactic) mass culling in public debates and in the academic ethical discourse (Cohen and Stassen 2016; Mepham 2016; Degeling et al. 2016), this is often countered by pointing out the allegedly unavoidable need of these practices against the backdrop of scientific (and thus supposedly incontestable) evidence (Latour 1999; Hinchliffe 2016: 30). Within such an objectivist understanding of disease (and health), illness or animal welfare and even animal lives come into play as a secondary moral issue only. Thus, (prophylactic) culling is a legitimized (although not entirely uncontested) measure to combat infectious diseases.

Let us now turn to Olivia's present problem she has to deal with: an initial outbreak of FMD. Basically, zoonotic diseases appear more pressing than FMD and other mere epizootics.

\footnotetext{
${ }^{8}$ The distinction between disease (objectivity of a pathology), illness (the experience of being ill), and sickness (the social role of a diseased person as meriting care, not having to work etc.) presents a widespread prerequisite in theories of medicine and in biomedical ethics (cf. Hofmann 2002).
} 
But from an ethical point of view things might turn out to be even more challenging. The relevant EU directive is unmistakable: "Food-and-Mouth disease is a highly contagious viral disease (...). Although foot-and-mouth disease has no public health importance, due to its exceptional economic importance, it is on the top of list A diseases of the Office International des Epizooties (OIE)" (Directive 2003/85/EC). Against the backdrop of such a frame, animal bodies are weighed against economic needs. From the beginning of 1992 on, vaccination of animals against FMD has been banned by the EU because it was alleged that (a) in vaccinated animals, like in infected individuals, antibodies are detectable which is a hurdle for the distinction of those vaccinated and those who are sick and contagious; and (b) even vaccinated individuals potentially transmit the virus (Bergevoet and van Asseldonk 2013). Instead, mass culling (of infected and of healthy animals for prophylactic reasons) presents a usual step in combatting FMD. Well-known examples for these policies are the outbreaks of FMD around the turn of the millennium in Great Britain and the Netherlands (Mepham 2016; Cohen and Stassen 2016).

The triad animal - owner - vet is framed and normatively charged by this kind of description. The detection of the FMD-virus causes a state of alert (it is a list A disease). Olivia is expected to respond by measures that are considered appropriate for such a state of alert: eradicating the virus by all means and provide for all contingencies. This also entails prophylactic stamping out suppressing the (moral) relevance of the individual animals' experiences and interests in survival. Although some research outcomes even suggest that the "necessity" of preventive culling is only given under specific circumstances, such as displaying clinical signs for a time period longer than 0.5 days, because transmission is not possible prior to this duration (Charleston et al. 2011: 728), a quick and effective procedure is deemed necessary to definitely provide for all contingencies. It becomes visible that the objectivist frame tends to conceal not only other frames but also research outcomes that do not conform to those practices that sustain this very frame. The "outbreak narratives" (Hinchliffe 2016: 29) shield themselves against suggestions of other legitimate responses to FMD.

To sum up, the objectivist conceptualization of health in veterinary medicine consists of a reductionism ${ }^{9}$ that excludes the animals as individual experiencing subjects as well as particular, socially determined relations between humans and animals. Instead, we have bodies that are in a potentially dangerous proximity. Combined with an "alert narrative", this reductionism leads to practices that are literally radical when it comes to combatting pathogens: either the microbes are locked out or eradicated, that is in case, the hosts and even the potential hosts are eradicated. As a hegemonic frame, it shields itself against other frames as well as scientific insights that do not conform to its essence. Olivia's practice as official veterinarian is determined and considered as justified by the prerequisites provided by this frame.

(ii). The Functionalist Conceptualization of Health: Health as Instrumental

One of Felicity's cows has a Bovine Ovarian Cyst (BOC). Such a cyst does usually not cause any suffering but inhibits fertility. Felicity's main expectations towards

\footnotetext{
${ }^{9}$ Drawing from Erinn Gilson (2011: 316), reductionism is conceived of as excluding particular ways of knowing (e.g. empathy) and excluding dimensions of health (the experience of well-being or illness). These exclusions are not moralized in a strict sense but have a methodological function in veterinary medicine. A critique of reductionism must, thus, be directed at the way or the extent of reduction but not on the very fact of reduction.
} 
veterinary medicine, thus, emerge neither from a concern about contagion nor from a concern for illness, that is, a "subjective feeling state of the individual referred to as symptoms" (Hofmann 2002: 653). Nevertheless, health is supposed to be pursued by a veterinary intervention: Felicity economically relies on the cow's ability to become pregnant (as precondition for the lactation performance) and conceives of this ability as part and parcel of health.

The statistical normality as sign for health reoccurs now in connection to productivity. While in Boorse the normalcy is a purely statistical one, Felicity identifies health with normal performance. Similarly to the objectivist frame, we can assume that the animal body is first of all a mere body, an object, but now its functions are most important. Against the backdrop of a human economic dependency on animals' productivity and efficiency due to tight margins, expectations towards veterinary medicine are mainly to maintain or restore efficient production. In turn, productivity becomes a sign for health. Veterinary interventions are thus justified by a diminished productivity, be it a slower growth in fattening pigs, be it a lower amount of eggs in chickens, or be it the absence of pregnancy in dairy cows.

From a historical perspective, food shortage as a looming existential problem shaped expectations towards veterinarians. After the Second World War, a substantial food scarcity occurred against the backdrop of a proceeded (however, significantly impaired) industrialization and capitalism. This led to the emergence of the production paradigm in agriculture (Thompson 1994) which formed a frame of health still of practical and moral significance. Food shortages appeared to be prior, and therefore "many argued that if veterinarians were to maintain their 'rightful place' on the farm, they had to embrace and assist intensification" (Woods 2013: 9). Nowadays, dairy farmers and other stakeholders in agriculture face tight margins and, thus, depend on efficiency guaranteed by bodily functions conforming to a given standard.

This functionalist frame is not only visible in practice when veterinarians meet expectations of dairy farmers or related professionals. Even in scientific papers, the descriptions of pathologies appear to be reliant on tacit presuppositions derived from the production paradigm. To make this visible, we review the paper Ovarian Cyst in dairy cows: old and new concepts for definition, diagnosis and therapy (Jeengar 2014). In this text, the BOC is described as "a major cause of reproductive failure in dairy cattle" (ibid.: 63). Pregnancy is the precondition of lactation performance. The BOC has become regarded as a widespread problem particularly in the last decades. The selection for production in breeding (pursuing a high lactation performance) has had the side effect of a susceptibility to this pathology (ibid.). The cows become prone to BOC due to breeding lines that should basically achieve the goal of maximizing profit. This is by far not the only pathology caused by intensification. "The emphasis on more outputs for less input systems has led to animal breeding programs that harness physiological traits favoring higher production at the expense of animal welfare issues such as lameness, mastitis, and dystocia." (Kimera and Mlangwa 2016: 2944). Hence, Felicity in her role as client of the veterinarian and her cow as patient can be considered as "products" of this particular frame.

The perspective of the animal and her illness or wellbeing does not and need not play a role. Jeengar even states that one should refrain from calling it a pathology: "Cysts are often diagnosed in the absence of clear clinical signs, therefore the term 'Cystic Ovarian Disease' no longer seems appropriate and should be replaced by the 
term 'Cystic Ovarian Follicle (COF)' which does not necessarily implicate a state of disease." (Jeengar 2014: 64). ${ }^{10}$ Here we can see that not only the illness/well-being of the animal plays a minor (if any) role but actually the basic physiological mechanism is not as important as the outcome for production. Beyond the absence of illness, the animal might be even called healthy in terms of the objective conceptualization of health. Reproduction is just a matter of time, the aberration from a normal state is just a phase, but it is too much time for the production process the cow is part of. This is also visible in the treatment recommendations the authors are giving in their article: Manual rupture of the cyst is not the gold standard "because it may result in trauma and haemorrhage". The problem here would not be the suffering for the animal but the fact that trauma and haemorrhage are again factors which play a role in "contributing to fertility reduction" (ibid.: 66).

To sum up, we can indicate that within the functionalist frame the instrumental nature of health is the primal concern of veterinary interventions. Health serves as a means to other ends, such as productivity, and gains its value in light of the end. A body is conceived of as healthy if it conforms to production statistics (e.g. lactation performance) instead of to a given species norm. This leads to another, however similar, kind of reductionism within this conceptualization of health. The BOC presents a relevant example to show that aberrations without any kind of symptom can be an indication for veterinary medical treatment. Suffering can but need not play a role for justifying veterinary interventions. Some "objective" pathologies might even be considered as inevitable in livestock animals and thus not as reason for veterinary interventions (e.g. mild behavioral problems).

\section{(iii). The Sentientistic Conceptualization of Health: Health as Well-Being}

We are now turning to Steven and his incipiently obese pug. At first glance, it might appear as besides the point to consider companion animals and their owners in a paper that is concerned with veterinarians as professionals in food chains. However, the aim of this section is to make visible a particular frame of conceiving health that is also significant in animals that appear in food chains. The example of the obese dog serves as vehicle for showing a different structure of justifying veterinary interventions than in the objectivist and the functionalist conceptualization of health. While these rely on the focus on bodily mechanisms that are compromised, the sentientistic conceptualization emphasizes the experience of the individual subject in terms of wellbeing or suffering.

Steven consults the veterinarian because he is attentive to his dog's bodily state and recognized the overweight in a quite early stage. For Steven, it is clear that it is not the mere fact that the animal's body contains too much fat tissue (compared to statistical average) that makes him contact the veterinarian. He considers himself obliged to take measures against the overweight because it is public knowledge that obesity potentially causes severe health problems like e.g. heart diseases, breathing difficulties, or metabolic disorders. However, for Steven it would be sufficient that the pug were restricted in his ability to move to consult the veterinarian. As a philosopher adhering to the pathocentristic paradigm (in which the ability to

\footnotetext{
${ }^{10}$ Jeengar's vote for de-pathologising the $\mathrm{BOC}$ is to be understood as taking distance from a concept of disease that equals "illness". As he points at the absence of a "state of disease" he refers to an understanding of a pathology that we will introduce in the upcoming section under the headline of the sentientistic conceptualization of health. However, as we argue, this frame is not primarily powerful when veterinary professionals are confronted with BOCs.
} 
suffer puts moral obligations upon us) he considers being deprived of exercising satisfying capacities as a moral problem he has to respond to as animal owner. ${ }^{11}$ Hence, the triad of animal - owner - veterinarian is embedded in a frame of health that is focused on illness in contrast to wellbeing. Illness presents an understanding of pathologies that emphasizes the individual experience of the patient (Hofmann 2002; Carel 2008, 2014). It is neither the "objective" aberration from a statistical normality nor the adulteration with microbes or the obstacle for gaining productive competitiveness that justifies veterinary interventions. The main aim of veterinary practice is the alleged wellbeing of the individual. This seems to be at odds with the kind of reductionism visible in the concept of $\mathrm{OH}$ adhering to an objectivist understanding of health. However, Sandøe et al. (2014) attempt to understand obesity in companion animals under the aegis of $\mathrm{OH}$ (although this concept emerged in the field of infectious diseases). Rooted in a "shared lifestyle" (ibid.: 612) of humans and animals, veterinary interventions are targeted towards pathological outcomes of breeding and keeping animals in ways that are detrimental for the individual's health. Sandøe et al. show that a shared etiology can refer not only to the contamination with microbes but also to social factors of health. However, we doubt that the original concept of $\mathrm{OH}$ fully complies with the notion of health that is at stake if we understand obesity as welfare issue. Proceeding from an objectivist understanding, $\mathrm{OH}$ is basically focused on (shared) bodily mechanisms.

Finally, we want to point out that the sentientistic frame in veterinary medicine is particularly significant when decision-making with regard to euthanasia is at stake. In some cases the termination of animal life is even conceived of as fundamental moral obligation (Grimm and Huth 2016: 96). If the alleged suffering of a family dog exceeds the level of what we consider acceptable, a preferably painless killing is deemed to be the morally right treatment. Notably, there is an increasing tendency to establish companion animal hospices and palliative care for animals; however, the question remains when we are obliged to kill an animal to avoid "unnecessary" suffering (Mullan and Fawcett 2017: 100).

To sum up, we can argue that this frame of health is focused on the individual experience of the animal as rationale for veterinary interventions. This approach to health is frequently called holistic as its logic is directed primarily to wellbeing but inevitably also embraces bodily functions (Nordenfelt 2006). However, this frame presents a kind of reductionism as it considers illness and wellbeing as prior; the body's functions count "only" insofar as they are the condition of possibility for wellbeing. ${ }^{12}$ Moreover, the body is even pushed to the margins of considerations at what moment decision with regard to euthanasia must be taken.

\section{(iv). Three Frames of Health Overlapping in Practice}

\footnotetext{
11 This passage is meant to make explicit the sentientistic frame's underlying philosophical assumptions. Unsurprisingly, it becomes obvious that seeking pleasure and avoiding suffering form the anchor of normativity (a crucial motif of animal ethics in different authors; see Palmer 2010; Singer 2011). In a similar vein but from a different perspective, this can also be linked to Martha Nussbaum's capability approach (2006). Within the latter approach, the good life is based on the exercise of fundamental capabilities that should not only be unhindered but also be supported. Nussbaum even claims the existence of a "dignity of needs" (ibid.: 278) indicating that positive obligations (beneficence) is no less morally significant than non-maleficence.

12 This becomes particularly obvious when we turn to the case of euthanasia in companion animals. Euthanasia is performed when we consider the suffering of an animal to make impossible a good life. This is not necessarily dependent on the "objective" state of a body and the instrumental functions this body shows.
} 
It would be a profound misunderstanding to conclude that these frames operate in pure juxtaposition. The aim of this paper is to point up different frames of health; therefore, we have described them in their difference. However, in practice they are overlapping.

First, take the example of (prophylactic) mass culling of livestock animals in the case of an outbreak of an infectious disease. We have indicated that such a practice mirrors an objectivist conceptualization of health. Yet such a practice does not go unchallenged when people refer to the sentientistic frame of health. Animals and their lives and wellbeing are part of the public debates about a decent reaction to such outbreaks. Animals are dominantly regarded as beings with a moral status, and thus the measures of stamping out are potentially seen as exaggerated and too drastic (Cohen and Stassen 2016). Moreover, there is the frequent claim to perform culling as painless as possible.

These concerns are also visible in the pertinent EU directive: "One of the Community's tasks in the veterinary field is to improve the state of health of livestock, thereby increasing the profitability of livestock farming and facilitating trade in animals and animal products. At the same time the Community is also a Community of values, and its policies to combat animal diseases must not be based purely on commercial interests but must also take genuine account of ethical principles." (Directive 2003/85/EC). This appears to be a clear statement. However, the practical outcome of this emphasis of ethical principles (whatever they may be) is frequently reduced to the intention to stamp out as painlessly as possible. ${ }^{13}$

Second, in practice, there is also a considerable overlapping of the functionalistic and the sentientistic conceptualization of health in livestock farming. If we take examples like lameness, mastitis, and dystocia - that are also considered as outcomes of breeding that seek to increase productivity - the rationale for veterinary intervention can also be the concern for the animals' suffering caused by these diseases. Moreover, like Steven when caring for his pug, livestock farmers could also be concerned about overweight and the pernicious outcomes for the animals' wellbeing. However, it is important to note that this would not be possible in an arbitrary way. Focusing on fattening pigs, the concern about obesity can - if at all - only occur from an uninvolved point of view. ${ }^{14}$ Pig farmers are dependent on their animals' weight, and the relevant health problems usually occur at an age that fattening pigs will not reach. In turn, someone who keeps dairy cows or sheep could consider herself to be responsible to care about overweight beyond the logic of an optimized use of animal bodies.

Third, it is clear that companion animals are not always treated according to the logic of the sentientistic frame of health. The breeding, keeping, and also veterinary treatment of pets can be intended to accommodate aesthetic predilections (Rollin 2006: 50). Pugs, to stick to our example, show in the usual breeding lines an increased susceptibility to the brachycephalic syndrome causing severe breathing difficulties (Sandøe et al. 2014: 107-8). Veterinarians can only try to treat the pertinent problem. Thus they do not change this practice; on the contrary, they economically benefit from it and sustain it by curing the pernicious outcome of such breeding. Yet this does not insinuate that veterinarians would opt for cruel breeding practices. Moreover, veterinarians are often confronted with a request that frequently causes moral distress: convenience euthanasia (Rollin 2006: 54). Such a request does not betray a

\footnotetext{
${ }^{13}$ Mepham (2016) points out that in mass culling the avoidance of pain can hardly be guaranteed, particularly due to time pressure.

${ }^{14}$ A literature search regarding "pigs" and "obesity" leads us almost exclusively to articles in which pigs serve as porcine models for human pathologies (e.g. Spurlock and Gabler 2008).
} 
sentientistic but rather a functionalistic understanding of an animal and her health: Either the animal contributes to my comfort or I want to get rid of her.

Finally, we want to point out that euthanasia frequently mirrors a sentientistic understanding of health. In livestock animals as well as laboratory animals (consider the "humane endpoint"), the termination of animal life is (like in companion animals) considered as moral obligation to avoid unnecessary suffering (Grimm and Huth 2016). If the alleged suffering of a family dog, a dairy cow, or a rat in the laboratory exceeds the level of what we consider acceptable, a preferably painless killing is deemed to be the morally right treatment. Similarly, zoonotic vectors are arguably reduced to their role as a potential threat to health. However, there is a virtually unambiguous consensus that the methods of stamping out should guarantee minimum stress and pain for the animals (Mepham 2016).

\section{Only One Health?! Health as an Example for Wittgenstein's Theory of Family Resemblance}

So far, it has been argued that health is framed differentially in various fields of veterinary practice. From an ethical point of view, this leads to the notion of different, normatively imbued, expectations towards veterinarians and thus different scopes of responsibility. Consequently, this analysis leads to the idea that we do not face logical or ethical inconsistencies in veterinary practice when animals are treated in different ways. Instead, the coexistence of various frames leads to the coexistence of various rationales and justifications of veterinary interventions. Therefore, it is futile and could even turn out to be psychologically pernicious to request full consistency from veterinarians' practice.

Moreover, it has been shown that there are significant overlaps between the three frames introduced in this paper. Livestock animals and alleged zoonotic vectors are also treated with regard to their ability to suffer. In turn, companion animals are sometimes conceived of as objects and are instrumental concerning e.g. human desires with regard to aesthetics. Another kind of instrumentality in companion animals is also visible for instance in animals that are used in animal assisted therapy, in guide dogs for the blind, or in police dogs. A veterinary intervention could be justified as maintaining the capacity to fulfill an animal's task as "worker". Nevertheless, the basic differences between the three frames remain obvious.

While $\mathrm{OH}$ promises to allow for regarding health as unequivocal phenomenon and target of medical intervention, this paper has pointed out variegated accounts to health exemplified by the siblings Olivia, Felicity, and Steven. But even though we can detect these very differences of expectations and practices in the various contexts, animal owners and, a fortiori, veterinarians are always and in any case concerned with health as rationale and justifying basis for veterinary interventions. Hence, drawing from Peter Schwartz (2007), it appears to be plausible to conceive of health as a model case for what Ludwig Wittgenstein famously calls family resemblance. Looking at the three siblings, we can doubt that "health" underlies one clear definition. Instead, health can be conceived of as a concept that denotes dispersed phenomena and related practices. As Wittgenstein puts it: "We do and can apply the same general word to different individuals [that is phenomena, $\mathrm{MH} / \mathrm{KW} / \mathrm{HG}$ ], not because the individuals share some identical features in common but because of overlapping similarities of properties." (Wittgenstein 1996: 31e). Wittgenstein's telling example is the concept "game" that refers to very different practices like chess, soccer, video games, or playing tag. It becomes visible that 
very different practices or objects might be subsumed under the same concept. Such an umbrella term bears "a complicated network of similarities overlapping and criss-crossing: sometimes overall similarities, sometimes similarities of detail" (Wittgenstein 1996: 32e).

Different phenomena are seen as health issues although different terms like disease, illness, and sickness (Hofmann 2002) show that the understandings of health-related problems exhibit major differences. In veterinary medicine, things turn out to be even more complicated than in human medicine since the different relations between humans and animals pre-determine and frame the notion of health and related expectations towards and obligations for veterinarians. One could deal with this issue as mere inconsistency in society and interpret veterinarians as hench(wo)men of current hegemonies. Alternatively, one can interpret their role as spanned between different values that are at stake in a pluralistic, sometimes even fragmented society and in a differential framing of veterinary responsibilities.

The ambiguity of the concept of health as teleological figure of veterinary medicine can be understood as a moral problem, as psychological burden, or as a source for change in practices and frames. There are always open possibilities for different narratives, different reliefs of values and re-thinking obligations towards animals in veterinary practice. This can be made visible particularly by means of an explication of the different frames of health and their overlapping. Steven's pug (eventually suffering from the brachycephalic syndrome) can be interpreted as the expression of human aesthetical standards that are considered outweighing some impairment in animals. Hence, we could also classify the pug as example for the functionalist conceptualization. This might also be a basis for critique of current breeding lines etc. Felicity's cows can and probably would also be targets of considerations that would fit into the sentientistic conceptualization of health so that the treatment of these animals will not only be motivated by economic considerations. And finally, we have seen that Olivia is not only legally bound to commit to safeguarding economy but is also expected (and obliged) to take actions that refer to sentientistically imbued moral opinions. However, to stick to the latter example, it is obvious that the individual (official) veterinarian is not capable of and, hence, not responsible for changing EU-wide or even internationally adopted measures to combat epidemics or zoonoses. Thus, the objective of dealing with culling in case of epidemics might be to handle the moral conflict that is not to be solved as such. Since one cannot gain clean hands in such a case, one has to cope with the moral tensions.

Consequently, the (re-) consideration of $\mathrm{OH}$ through the lens of three frames of health could be more complex than in the traditional naturalistic understanding of $\mathrm{OH}$ but also more sensitive to different fields of veterinary practices. Understanding veterinary medicine as dispersed in various fields with different moral obligations and constraints increases the complexity of veterinary ethics. Moreover and admittedly, a differential framing of veterinary practices is in danger of leading to a compartmentalization of different practices. This could potentially entail a pseudo-justification of treatments that are pernicious for animals as allegedly inevitable within a particular frame. However, this would present a profound misunderstanding of the argumentation of this paper. By contrast, we wanted to point out that a more sensitive account to various fields of veterinary medicine contributes to a targeted reflection of the different scopes and the constraints of veterinary responsibility. Furthermore, it reveals the problematic pretenses of $\mathrm{OH}$ when promising an all-inclusive account to health in animals and humans that is not thwarted by tensions between different kinds of health and different needs and interests beyond health (not the least economic ones). But an awareness of this complexity can contribute to a reduction of moral distress since veterinarians that are 
mindful of this diversity of scopes can refrain from applying the same ethical expectations or criteria to all kinds of practices - which would entail the experience of fundamental logical and moral inconsistencies.

\section{Conclusion}

It has not been the aim of this paper to argue against $\mathrm{OH}$ as a professional imperative. $\mathrm{OH}$ can serve as a crucial source for informing veterinary practices with regard to the inevitable interdependence of human and animal health in a shared environment. However, drawing from Rosenberg's concept of "framing disease" (1997), we have argued that the concept of health can show various significations and functions. This variety is neither to be misconceived as a mere juxtaposition nor as a logical or ethical inconsistency. The objectivist, the functionalist, and the sentientistic frame show differences and might appear mutually exclusive, but they have open edges and can overlap considerably. It is possible and even likely that Olivia and Felicity do also consider wellbeing in their decisions and expectations towards veterinary medicine. In turn, Steven will probably also think about financial constraints and evaluate whether a costly treatment of his pug "pays off".

Importantly, "health" has been conceived of as a teleological figure justifying veterinary interventions. In contrast to $\mathrm{OH}$, we proposed to understand this concept as complex and multi-layered. $\mathrm{OH}$ is not in an opposition to our account but covers only a - though significant - part of health. Therefore, veterinary practice is framed differentially. "Moral distress" of the professionals as described e.g. by Rollin (2006) can be reduced if veterinarians, but also animal owners and the public, acknowledge the multiple scopes and the structural predetermination of veterinary responsibility. The different frames should not be played against each other but are coexistent contexts of justifications with their own justificatory power, but also with their immanent limitations due to an inevitable reductionism in each of them.

Funding Information Open access funding provided by University of Veterinary Medicine Vienna.

\section{Compliance with Ethical Standards}

Conflict of Interest On behalf of all authors, the corresponding author states that there is no conflict of interest.

Open Access This article is distributed under the terms of the Creative Commons Attribution 4.0 International License (http://creativecommons.org/licenses/by/4.0/), which permits unrestricted use, distribution, and reproduction in any medium, provided you give appropriate credit to the original author(s) and the source, provide a link to the Creative Commons license, and indicate if changes were made.

\section{References}

American Veterinary Association. 2008. One health: A new professional imperative. One Health Initiative Task Force Final Report. https://www.avma.org/KB/Resources/Reports/Documents/onehealth_final.pdf. Accessed 28 January 2018.

Bergevoet, Ron H.M. and Marcel A.P.M. van Asseldonk. 2013. https:/www.oecd.org/tad/agriculturalpolicies/ECONOMIC\%20EVALUATION\%20OF\%20FMD\%20CONTROL\%20STRATEGIES\%20IN\%20 THE\%20NETHERLANDS.pdf. Accessed 4th Jan 2018. 
Boorse, Christopher. 1977. Health as a theoretical concept. Philosophy of Science 44: 542-573.

Boorse, Christopher. 1997. A rebuttal on health. In What is disease? ed. James M. Humber and Robert F. Almeder, 1-134. New York: Humana Press.

Bresalier, Michael, Angela Cassidy, and Abigail Woods. 2015. One Health in History. In One Health. In The Theory and Practice of Integrated Health Approaches, ed. Jakob Zinsstag, Esther Scelling, Davi WaltnerToews, Maxine Whittaker, and Marcel Tanner, 1-15. Boston: Oxfordshire.

Broom, Donald. 2007. Welfare in relation to feelings, stress and health. REDVET. Revista electrónica de Veterinaria, VIII, 12B. http:/www.veterinaria.org/revistas/redvet/n121207B/BA018ing.pdf. Accessed 30 March 2016.

Buller, Henry. 2017. Antrimicrobial Use. Response. In Veterinary Ethics. Navigating Tough Cases, ed. Siobhan Mullan and Anne Fawcett, 432-433. Sheffield: 5m Publishing.

Canguilhem, Georges. 1989. The Normal and the pathological. New York: Zone Books.

Carel, Havi. 2008. Illness. The cry of the flesh. London: Routledge.

Carel, Havi. 2014. The philosophical role of illness. Metaphilosophy 45 (1): 20-40.

Charleston, Bryan, Bartolomies M. Bankowski, Simon Gubbins, Margo E. Chase-Topping, David Schley, Richard Howey, Paul V. Barnett, Debi Gibson, Nocholas D. Juleff, and Mark E.J. Woolhouse. 2011. Relationship between clinical signs and transmission of an infectious disease and the implications for control. Science 332 (6030): 726-729.

Cohen, Nina E., and Elsbeth N. Stassen. 2016. Public moral convictions about animals in the Netherlands: Culling healthy animals as a moral problem. In The end of animal life: A start for ethical debate. Ethical and societal considerations on killing animals, ed. Franck L.B. Meijboom and Elsbeth N. Stassen, 137-148. Wageningen: Wageningen Aacademic Publishers.

Degeling, Chris, Zohar Lederman, and Melanie Rock. 2016. Culling and the common good: re-evaluating harms and benefits under the one health paradigm. Public Health Ethics 9 (3): 244-254.

Emanuel, Linda L., and Ezekiel J. Emanuel. 1992. Four models of the physician-patient relationship. Journal of the American Medical Association 267: 2221-2226.

Engelhardt, H. Tristam. 1975. The Concepts of Health and Disease. In Evaluation and Explanation in the Biomedical Sciences, ed. H. Tristam Engelhardt Jr. and Stuart F. Spicker, 125-141. Dordrecht: Springer.

EU Council Directive 2003/85/EC on Community measures for the control of foot-and-mouth disease repealing Directive 85/511/ EEC and Decisions 89/531/EEC and 91/665/EEC and amending Directive 92/46/EEC. 2003. https://eur-lex.europa.eu/legalcontent/EN/TXT/PDF/?uri=CELEX:32003L0085\&from=EN. Accessed 9 January 2018.

Fawcett, Ann, and Siobhan Mullan. 2018. Managing moral distress in practice. In Practice 40 (2): 34-36.

Forrest, Christopher B. 2014. A Living Systems Perspective on Health. Medical Hypotheses 82 (2): $209-214$.

Gilson, Erinn. 2011. Vulnerability, Ignorance, and Oppression. Hypatia 26 (2): 308-332.

Grimm, Herwig, and Martin Huth. 2016. The 'significance of killing' versus the 'death of an animal'. In The end of animal life: a start for an ethical debate. Ethical and societal considerations on killing animals, ed. Franck L.B. Meijboom and Elsbeth N. Stassen, 79-101. Wageningen: Wageningen Academic Publishers.

Haraway, Donna. 2008. When Species Meet. Minneapolis: University of Minnesota Press.

Hinchliffe, Steve. 2016. More than one world, more than one health: Re-configuring interspecies health. Social Science and Medicine 129: 28-35.

Hinchliffe, Steve, Nick Bingham, John Allen, and Simon Carter. 2017. Pathological Lives. Disease, space and biopolitics. Oxford: Wiley Blackwell.

Hofmann, Bjørn. 2002. On the Triad Disease, Illness and Sickness. Journal of Medicine and Philosophy 27 (6): 651-673.

Huth, Martin. 2016. Justifying Veterinary Interventions. The Normative Concepts of Health. In Food Futures. Ethics, Science and Culture, ed. Anna S. Olsson, Sofia M. Araújo, and M. Fatima Vieria, $279-284$. Wageningen: Wageningen Academic Publishers.

Huth, Martin. 2018. The Recognition of Animals as Patients - The Frames of Veterinary Medicine. In Professionals in Food Chains. Ethics, Roles and Responsibilities, ed. Svenja Springer and Herwig Grimm, 243-248. Wageningen: Wageningen Academic Publishers.

Jeengar, Kumar M. 2014. Ovarian cyst in dairy cows: old and new concepts for definition, diagnosis and therapy. Animal Reproduction 11 (2): 63-73.

Kimera, Sharadhuli I., and James E.D. Mlangwa. 2016. Veterinary Ethics. In Encyclopedia of Global Bioethics, ed. Henk ten Have, 2937-2947. Dordrecht: Springer.

Latour, Bruno. 1999. Pandora's Hope. Essays on the Reality of Science Studies. Cambridge: Harvard University Press.

Mepham, Ben. 2016. Morality, morbidity and mortality: an ethical analysis of culling nonhuman animals. In The end of animal life: a start for an ethical debate, ed. Franck L.B. Meijboom and Elsbeth N. Stassen, 115-136. Wageningen: Wageningen Academic Publishers. 
Mullan, Siobhan, and Anne Fawcett. 2017. Veterinary Ethics: Navigating Tough Cases. Sheffield: $5 \mathrm{~m}$ Publishing.

Nordenfelt, Lennart. 2006. Animal and human health and welfare. A comparative philosophical analysis. Wallingford: Cabi.

Nussbaum, Martha C. 2006. Frontiers of Justice. Disability, Nationality, Species Membership. Cambridge: The Belknap Press of Harvard University Press.

Palmer, Clare. 2010. Animal Ethics in Context. New York: Columbia University Press.

Rollin, Bernard. 2006. An Introduction to Veterinary Medical Ethics: Theory and Cases. Ames: Blackwell.

Rosenberg, Charles E. 1989. Framing Disease: The Creation and Negotiation of Explanatory Schemes. The Milbank Quarterly 67: 1: 1-1:15.

Rosenberg, Charles E. 1997. Introduction: Framing Disease. Illness, society, and history. In Framing Disease. Studies in Cultural History, ed. Chalres E. Rosenberg and Janet Golden. New Brunswick: Rutgers University Press.

Sandøe, Peter., Clare Palmer, Sandra A. Corr, Arne Astrup, and Charlotte R. Bjørnvad. 2014. Canine and feline obesity: a One Health perspective. Veterinary Record 175 (24): 610-616.

Schramme, Thomas. 2017. Goals of Medicine. In Handbook of Philosophy and Medicine, ed. Thomas Schramme and Steven Edwards, 122, Dordrecht-128. Springer.

Schwartz, Peter. 2007. Decision and discovery in defining 'disease'. In Establishing Medical Reality: Essays in the Metaphysics and Epistemology of Biomedical Science, ed. Harold Kincaid and Jennifer McKitrick, 4764. Dordrecht: Springer.

Singer, Peter. 2011. Practical Ethics. Cambridge: Cambridge University Press.

Spurlock, Michael E., and Nicholas K. Gabler. 2008. The Development of Porcine Models of Obesity and Metabolic Syndrome. American Society for Nutrition 138 (2): 397-402.

Thompson, Paul. 1994. The Spirit of the Soil. Agriculture and Environmental Ethics. London: Routledge.

Verweij, Marcel, and Franck L.B. Meijboom. 2015. One Health as Collective Responsibility. In Know your Food. Food Ethics and Innovation, ed. Diana E. Dumitras, Ionel M. Jitea, and Stef Aerts, 144-149. Wageningen: Wageningen Academic Publishers.

Whittaker, Maxine. 2015. The role of social sciences in One Health - reciprocal benefits. In One Health: the theory and practice of integrated health approaches, ed. Jakob Zinsstag, Esther Schelling, David WaltnerToews, Maxine Whittaker, and Marcel Tanner, 60-72. Wallingford: Cabi.

Wittgenstein, Ludwig. 1996. Philosophical Investigations. Oxford: Basil Blackwell.

Woods, Abigail. 2013. The History of Veterinary Ethics in Britain, ca. 1870-2000. In Veterinary and Animal Ethics. Proceedings of the First International Conference on Veterinary and Animal Ethics, September 2011, ed. Christopher Wathes, Sandra Corr, Stephen May, Steven McCulloch, and Martin Whiting, 3-18. Oxford: Wiley-Blackwell.

Zinsstag, Jakob, David Waltner-Toews, and Marcel Tanner. 2015. Theoretical Issues of One Health. In One Health. The Theory and Practice of Integrated Health Approaches, eds. Jakob Zinsstag, Esther Scelling, Davi Waltner-Toews, Maxine Whittaker, and Marcel Tanner, 16-25. Oxfordshire: Cabi.

Publisher's Note Springer Nature remains neutral with regard to jurisdictional claims in published maps and institutional affiliations. 